\title{
An Eye on Travel: An Overview of Travel-Related Ocular Complications
}

\author{
John Zhi Ming Tang ${ }^{1}$, Gerard T. Flaherty ${ }^{1,2^{*}}$ \\ ${ }^{1}$ School of Medicine, National University of Ireland Galway, Ireland \\ ${ }^{2}$ School of Medicine, International Medical University, Kuala Lumpur, Malaysia \\ Corresponding Author: Gerard T. Flaherty, MD, Professor, School of Medicine, National University of Ireland \\ Galway, Ireland. Tel: +35391495469, Email: gerard.flaherty@nuigalway.ie
}

Received June 14, 2017; Accepted August 20, 2017; Online Published September 11, 2017

\begin{abstract}
Travellers are at risk of a diverse range of environmental and infectious conditions, some of which may affect the eyes and lead to blindness in severe cases. Travel-related ocular infections include onchocerciasis, leishmaniasis, cysticercosis, trachoma, dengue, loiasis, and leptospirosis. Travel medicine advisers should also recognise other hazards encountered during travel which may adversely affect the eye. These include recreational activities such as high altitude trekking, bungee jumping, skiing, scuba diving, and sun exposure. There is a subset of travellers who have underlying eye conditions, which predispose them to complications during international travel, including angle-closure glaucoma, and expansion of intraocular gas from previous vitreoretinal surgery. Contact lens wearers have a greater risk of ocular infection and corneal erosion during travel, especially where hygiene standards are low. Despite the susceptibility of the eye to infection, traumatic injury and environmental damage during international travel, this topic is not frequently discussed in the context of pre-travel consultations. Travel medicine professionals should have a reasonable knowledge of the major ocular risks associated with travel overseas.

Keywords: Altitude, Contact Lenses, Eye Diseases, Eye Infections, Travel
\end{abstract}

Citation: Tang JZM, Flaherty GT. An eye on travel: an overview of travel-related ocular complications. Int J Travel Med Glob Health. 2017;5(3):7476. doi:10.15171/ijtmgh.2017.16.

\section{Introduction}

Travellers are exposed to a wide variety of environmental and infectious conditions, some of which may affect the eyes. This article introduces travel-related ocular risks, with a focus on more important conditions which may be sight-threatening, but preventable with adequate traveller precautions. Tropical ocular infections include onchocerciasis, leishmaniasis, cysticercosis, pythiosis, ophthalmomyiasis, filariasis, trachoma, dengue, loiasis, and leptospirosis. Travel medicine advisers should recognise other ocular hazards such as recreational activities such as high altitude trekking, ${ }^{1,2}$ bungee jumping, ${ }^{3,4}$ skiing, and scuba diving. ${ }^{5}$ Prolonged sun exposure may result in cataracts or solar retinopathy, especially during solar eclipse tourism when individuals may inadvertently stare at the sun. ${ }^{6}$ Additionally, there is a subset of travellers with underlying eye conditions, which predispose them to complications during international travel, including angleclosure glaucoma, ${ }^{7}$ and expansion of intraocular gas from previous vitreoretinal surgery. ${ }^{8}$ Contact lens users also face additional risks of ocular infection and corneal erosion during travel. ${ }^{9}$

\section{Travel-Related Eye Infections}

Eye infections in travellers are most commonly associated with swimming activities. Unique microbes found in endemic countries place travellers at risk of acquiring infections which are unfamiliar to many medical practitioners. Such cases often go unrecognised, and diagnostic delay may be detrimental. Some of these ocular infections are potentially fatal and prompt recognition is essential. Onchocerciasis is a disease caused by infection with the parasitic worm Onchocerca volvulus, and it is the second leading infectious cause of blindness worldwide. ${ }^{10}$ The designation 'river blindness' stems from the fact that it is spread by the bite of a black fly, Simulium yahense, which lives near fast-flowing rivers. Microfilariae migrate to the surface of the cornea giving rise to ocular manifestations such as punctate or sclerosing keratitis, depending on the chronicity of the infection. There are currently no vaccinations or medications for prevention or treatment of onchocerciasis. Recommended prevention strategies include personal protective measures against biting insects, and minimising travel to areas which are particularly endemic, such as Ghana in sub-Saharan Africa.

Copyright $\odot 2017$ The Author(s). This is an open-access article distributed under the terms of the Creative Commons Attribution License (http:// creativecommons.org/licenses/by/4.0), which permits unrestricted use, distribution, and reproduction in any medium, provided the original work is properly cited. 
Dengue fever, chikungunya and malaria are endemic in many countries in South-East Asia, Africa and South America and pose a threat to local residents and international visitors. Dengue infection often presents with retro-orbital pain and may be complicated by a rare form of the disease which can progress to permanent visual impairment. ${ }^{11}$ Similarly, chikungunya may produce ocular symptoms, the most common being anterior uveitis, conjunctivitis and retinitis. ${ }^{12}$ Zika virus infection, also transmitted by the daytime bite of the Aedes mosquito, is commonly presented with fever and conjunctivitis with red eyes and bilateral non-purulent ocular exudate. Malarial retinopathy is a complication in children with cerebral malaria. The main components of malarial retinopathy are retinal whitening, vessel changes, retinal haemorrhages, and papilloedema. The first two listed abnormalities are specific to malaria and are not described in other ocular or systemic conditions. ${ }^{13}$

There should be a high index of suspicion for dengue, chikungunya and malaria in febrile travellers returning from endemic areas. It would be prudent to systematically screen for maculopathy or other ocular pathology in these returned travellers, especially when visual disturbances arise. ${ }^{14}$ There is an increased risk of eye disorders, such as cataracts and retinal conditions, for users of specific anti-malarials such as chloroquine. ${ }^{15}$

\section{Travel Adventure Activities and Eye Disease}

A variety of ocular conditions may be precipitated by the travel-related activities undertaken by the traveller. Snowblindness is an acute form of kerato-conjunctivitis secondary to unprotected exposure to ultraviolet light. It has been described as 'sunburn of the eye which can be extremely painful.' ${ }^{16}$ Its prevalence in snow-laden environments is due to the increased UV exposure by light reflecting from snow, among other factors including high altitude and clear skies. ${ }^{17}$ As delays may occur between exposure to UV light and symptom onset, it is important for travellers to be aware that damage could already have occurred with prior exposure. Snow-blindness usually presents with hyperaemic, gritty eyes which become more painful in strong light. If left untreated, the condition may deteriorate to total blindness. Immediate treatment involves local cooling, lubricating drops, antibiotic ointment, rest and light avoidance. ${ }^{16}$ Additional care should be taken to prevent secondary infection. A simple preventive measure involves continuous daytime use of wraparound sunglasses or goggles which block both UVA and UVB rays. Soot can be applied to the inside to reduce glare, similar to the practice in the Inuit Eskimo population.

\section{The Eye at High Altitude}

High-altitude environments present additional ocular risks to the unwary traveller and these have been comprehensively reviewed by Izadi and colleagues. ${ }^{18}$ Common high-altitude eye problems include high altitude retinopathy, ${ }^{19}$ optic disc swelling and dry eyes. High altitude retinopathy is manifest by engorged and tortuous retinal vessels secondary to hyperviscosity due to polycythaemia, ${ }^{20}$ and may present with retinal haemorrhages, cotton wool spots and papilloedema. The traveller's visual acuity may be preserved or it may be threatened if a macular haemorrhage occurs. The increased prevalence of dry eyes at altitude has been associated with both a decrease in tear production, as well as accelerated tear evaporation due to the dry and windy environment. ${ }^{21}$ Dry eyes are often merely an irritation to the traveller; however, severe episodes increase susceptibility to eye infection, and can be distressing, especially when accompanied by deteriorating vision. Travellers with comorbidities are more vulnerable to the effects of hypoxia at altitude and may be advised to avoid such environments. ${ }^{22}$ For individuals who are susceptible to dry eyes, minimal contact lens usage should be recommended. Additionally, lubricating eye drops should be provided for symptomatic relief of dry eyes. More viscous ointments provide prolonged relief at the expense of visual acuity. ${ }^{16}$ The use of goggles and wraparound sunglasses should be advised as they can also limit the evaporation of tears.

\section{Traumatic Eye Injuries}

Bungee-jumping is a popular extreme adventure travel activity in countries such as New Zealand. Bungee-associated ocular injury is believed to be due to a sudden increase in venous pressure from the rapid acceleration and deceleration over the short period of a jump..$^{23}$ Intravenous pressures can rise to more than $100 \mathrm{~mm} \mathrm{Hg}$ following a rapid-3G deceleration during a bungee jump, and this may result in intraocular haemorrhages. ${ }^{3}$ Tractional retinal detachment and its related complications can also arise from the mechanical effect of the gravitational force on vitreous movement. Traumatic ocular injury has also been inflicted by the bungee cord itself. ${ }^{24}$ Travellers planning a bungee jump should be forewarned about these potential complications and advised to ensure that stringent safety guidelines are adhered to by bungee service providers. Protective eyewear should also be recommended to prevent traumatic injury.

\section{Advising Travellers With Eye Disease}

Pre-existing ocular conditions increase susceptibility to several travel-related eye problems. Glaucoma is a condition that causes damage to the optic nerve associated with excessive intraocular pressure. The presence of glaucoma exacerbates insults to the optic nerve when exposed to a hypoxic environment such as high altitude. ${ }^{21}$ There is evidence of exacerbation of angle-closure glaucoma on long-haul flights as the dimly lit environment causes mydriasis, precipitating a pupil block. ${ }^{7}$ This principle could be applied to a wide range of travel-related activities in low ambient light environments and warrants additional precautions. Oral acetazolamide has been suggested as a viable alternative to the use of beta-blockers and is used in some trekkers to prevent acute mountain sickness. ${ }^{21}$ Medical gases such as perfluoropropane or sulphur hexafluoride are often used in vitreoretinal surgery. This presents risks to air travellers due to Boyle's law, which ordains that, as the cabin pressure at flight altitudes is lower than the sea level, any intraocular gas bubbles will expand and increase the intraocular pressure. Patients with 
recent vitreoretinal surgery involving intraocular gas should be strongly advised not to undertake air travel, regardless of the volume of gas applied. ${ }^{25}$

\section{Contact Lens Use During Travel}

Contact lens users have a greatly increased risk of bacterial, viral, fungal, and amoebic infections. This is mainly due to the inability to maintain proper lens hygiene during travel, especially in wilderness environments. The additional complications of freezing lenses and solutions as challenges to hygiene at high altitude environments have been discussed in the literature. ${ }^{9}$ The lifespan of contact lenses is greatly reduced by cold and dry winds, and a dried lens can fracture in the eye, increasing the risk of corneal abrasion and infection. Sleeping with contact lenses in situ can also excessively desiccate the lens, causing it to adhere to the cornea. Travellers on long trips commonly fall asleep while wearing contact lenses, and should be advised to remove their lenses prior to falling asleep, or to avoid using them while in transit, especially in the low relative humidity of an aircraft cabin. The use of contact lenses during exposure to water pre-disposes to infection, as waterborne micro-organisms can adhere to the lens. ${ }^{26}$ This is a greater issue when swimming in stagnant ponds or lakes in tropical countries due to the wide variety of micro-organisms present. The risk of infection can be reduced by adopting measures such as washing hands regularly and for an adequate duration with soap, washing the lens container, using daily disposable lenses and wearing airtight goggles when swimming.

\section{Conclusion}

The eye is susceptible to infection, injury and environmental insults during international travel, yet this topic is not frequently discussed in the travel medicine literature. Travel medicine practitioners should have a working knowledge of the major ocular risks associated with travel overseas.

\section{Authors' Contributions}

Both authors contributed equally to the conception, planning, writing and editing of the article. The final version was read and approved by both authors.

\section{Conflict of Interest Disclosures}

None declared.

\section{Ethical Approval}

Not applicable.

\section{Funding/Support}

None received.

\section{References}

1. Willmann G, Ivanov IV, Fischer MD, et al. Effects on colour discrimination during long term exposure to high altitudes on $\mathrm{Mt}$ Everest. Br J Ophthalmol. 2010;94(10):1393-1397. doi:10.1136/ bjo.2009.178491.

2. Bosch MM, Barthelmes D, Merz TM, et al. High incidence of optic disc swelling at very high altitudes. Arch Ophthalmol. 2008;126(5):644-650. doi:10.1001/archopht.126.5.644

3. Hassan HM, Mariatos G, Papanikolaou T, Ranganath A, Hassan
H. Ocular complications of bungee jumping. Clin Ophthalmol. 2012;6:1619-1622. doi:10.2147/opth.s33169.

4. Van Rens E. Traumatic ocular haemorrhage related to bungee jumping. $\mathrm{Br}$ J Ophthalmol. 1994;78(12):948. doi:10.1136/ bjo.78.12.948.

5. Yeoh R, Yeoh R, Singh M. Barotraumatic ocular haemorrhage sustained while scuba diving. Clin Exp Ophthalmol. 2008;36(6):581-582. doi:10.1111/j.1442-9071.2008.01835.x.

6. Moran S, O'Donoghue E. Solar retinopathy secondary to sungazing. BMJ Case Rep. 2013;2013:bcr2012008402. doi:10.1136/bcr2012-008402.

7. Turnbull AM, Smith M, Ramchandani M. Angle-closure glaucoma on long-haul flights. JAMA Ophthalmol. 2014;132(12):14741475. doi:10.1001/jamaophthalmol.2014.3501

8. Houston S, Graf J, Sharkey J. Commercial air travel after intraocular gas injection. Aviat Space Environ Med. 2012;83(8):809-810.

9. Bauer IL. Contact lens wearers' experiences while trekking in the Khumbu region/Nepal: a cross-sectional survey. Travel Med Infect Dis. 2015;13(2):178-184. doi:10.1016/j.tmaid.2014.12.005

10. Centers for Disease Control. Onchocerciasis. Available at: http:// www.cdc.gov/parasites/onchocerciasis. Accessed May 12, 2017.

11. Lim WK, Mathur R, Koh A, Yeoh R, Chee SP. Ocular manifestations of dengue fever. Ophthalmology. 2004;111(11):2057-2064. doi:10.1016/j.ophtha.2004.03.038.

12. Mahendradas P, Avadhani K, Shetty R. Chikungunya and the eye: a review. J Ophthalmic Inflamm Infect. 2013;3(1):35. doi:10.1186/1869-5760-3-35.

13. Beare NA, Taylor TE, Harding SP, Lewallen S, Molyneux ME. Malarial retinopathy: a newly established diagnostic sign in severe malaria. Am J Trop Med Hyg. 2006;75(5):790-797.

14. Tan SY, Kumar G, Surrun SK, Ong YY. Dengue maculopathy: a case report. Travel Med Infect Dis. 2007;5(1):62-63. doi:10.1016/j. tmaid.2006.01.017.

15. Schneider C, Adamcova M, Jick SS, et al. Use of anti-malarial drugs and the risk of developing eye disorders. Travel Med Infect Dis. 2014;12(1):40-47. doi:10.1016/j.tmaid.2013.07.007.

16. Morris DS, Mella S, Depla D. Eye problems on expeditions. Travel Med Infect Dis. 2013;11(3):152-158. doi:10.1016/j. tmaid.2013.03.009.

17. Guly HR. Snow blindness and other eye problems during the heroic age of Antarctic exploration. Wilderness Environ Med. 2012;23(1):77-82. doi:10.1016/j.wem.2011.10.006.

18. Izadi M, Pourazizi M, Alemzadeh-Ansari MH. Ocular Problems in High-Altitude Traveling: A Review With Focus on Management. Int J Travel Med Glob Health. 2017;5(2):41-45. doi:10.15171/ ijtmgh.2017.09.

19. Tingay DG, Tsimnadis P, Basnyat B. A blurred view from Everest. Lancet. 2003;362(9400):1978. doi:10.1016/S01406736(03)15017-9.

20. Morris DS, Somner J, Donald MJ, et al. The eye at altitude. Adv Exp Med Biol. 2006;588:249-270.

21. Mader TH, Tabin G. Going to high altitude with preexisting ocular conditions. High Alt Med Biol. 2003;4(4):419-430. doi:10.1089/152702903322616173.

22. Mieske K, Flaherty G, O'Brien T. Journeys to high altitude--risks and recommendations for travelers with preexisting medical conditions. J Travel Med. 2010;17(1):48-62. doi:10.1111/j.17088305.2009.00369.x.

23. Jain BK, Talbot EM. Bungee jumping and intraocular haemorrhage. Br J Ophthalmol. 1994;78(3):236-237.

24. Aldave AJ, Gertner GS, Davis GH, Regillo CD, Jeffers JB. Bungee cord-associated ocular trauma. Ophthalmology. 2001;108(4):788792. doi:10.1016/S0161-6420(00)00656-4.

25. Muzychuk AK, Adatia FA, Ford BA, Kherani AM. Commercial air travel with a small intravitreous gas bubble. Arch Ophthalmol. 2011;129(6):805-820. doi:10.1001/archophthalmol.2011.144.

26. Weissman BA, Mondino BJ. Risk factors for contact lens associated microbial keratitis. Cont Lens Anterior Eye. 2002;25(1):3-9. doi:10.1016/S1367-0484(01)00002-9. 